\title{
Critical Literature Review: Preparation Strategies
}

\section{Type of article: Conference abstract}

\author{
Syed Tajuddin Bin Syed Hassan ${ }^{1}$, Saliza Mohd Elias ${ }^{2}$, Jalalian Mehrdad ${ }^{3}$ \\ 1 Department of Nursing and Rehabilitation, Faculty of Medicine and Health Sciences, \\ Universiti Putra Malaysia. \\ 2 Department of Environmental and Occupational Health, Faculty of Medicine and \\ Health Sciences, Universiti Putra Malaysia. \\ 3 Mehrafarin Scientific Publishing, Kish Island, Iran. \\ Email: stshasan@upm.edu.my
}

\begin{abstract}
The imperative needs for, and characteristics of an effective critical literature review, provide the foreground baseline deliberation. A visual model depicting synthesized major modular components of a research project delineate impact points of literature review inputs. The three major modules represent preparation, data capture, and data rendering-analysis-interpretation phases of research. Within each module, the literature review elements to be incorporated are elaborated. Steps and optimal articulation-action strategies are highlighted and embedded with examples from literature and theses. Development of competency and efficacy in critiquing and evaluating, which comprised mandatory skills to acquire, is especially focussed.
\end{abstract}

Keywords: Publishing, critical literature review, competency critiquing, research, visual model.

\section{Declaration of conflicts}

This article is a keynote presented at the International Conference on Health Sciences and Medical Technologies 2017 ICHSMT'17.

\section{Authors' biography}

Prof Dr Syed Tajuddin Bin Syed Hassan, Department of Nursing and Rehabilitation, Faculty of Medicine and Health sciences, Universiti Putra Malaysia.

Dr Saliza Mohd Elias PhD, Department of Environmental and Occupational Health, Faculty of Medicine and Health sciences, Universiti Putra Malaysia.

Dr. Md Jalalian Mehrdad, Director, Mehrafarin Scientific Publishing, Kish Island, IR Iran. Editor-in Chief of Electronic Physician Journal, Mashhad, IR Iran.

\section{References}

No references 